\title{
Effect of processing on microstructure and wear characteristics of an $\mathrm{Al}-4 \cdot 5 \mathrm{Cu}-10 \mathrm{~Pb}$ alloy
}

\author{
J P PATHAK and S N OJHA \\ Centre for Advanced Study, Department of Metallurgical Engineering, Banaras Hindu \\ University, Varanasi 221005 , India \\ MS received 7 August 1995
}

\begin{abstract}
An $\mathrm{Al}-4 \cdot 5 \mathrm{Cu}-10 \mathrm{~Pb}$ alloy was processed by sprạy forming as well as impeller mixing followed by chill casting methods. The microstructure, mechanical properties and dry sliding wear characteristics of the alloy were evaluated. The spray formed alloy showed an equiaxed grain morphology with a uniform dispersion of lead particles in the matrix phase. In contrast a cellular-dendritic morphology of the primary phase was the characteristic feature of the alloy processed by impeller mixing and chill casting method. The spray formed alloy indicated its superior mechanical properties and low wear rate particularly at higher applied load and sliding velocity. The possible reason for this behaviour is discussed in the light of microstructure of the alloy and the nature of the worn out surfaces of the wear test specimens.
\end{abstract}

Keywords. Spray forming; impeller mixing; solidification; microstructure; particle dispersion: wear.

\section{Introduction}

The microstructural control, through dispersion of second phase particles of low melting metals in Al-matrix, provides an exciting new opportunity in development of materials with superior wear property. The particles of low melting metals viz. $\mathrm{Sn}, \mathrm{Pb}$, $\mathrm{Cd}$ etc are smeared into a thin lubricating film on the mating surfaces which protects the matrix phase from further wear (Forrester 1960; Pratt 1973; Pathak et al 1986). However, the formation of a continuous lubricating film at an early stage of wear considerably depends on the size and size distribution of second phase particles (Pathak and Tiwari 1992; Pathak et al 1993).

Earlier attempts to synthesize $\mathrm{Al}-\mathrm{Pb}$ alloys by the conventional casting route had limited success (Eppich et al 1971; Borbunov et al 1973). The phase diagram of this alloy system exhibits a monotectic reaction and liquid immiscibility over a wide range of temperature and composition (Mondolfo 1976). In addition, a large difference in the densities of the constituent phases results in a rapid separation of $\mathrm{Al}$ and $\mathrm{Pb}$-rich phases during slow cooling of a casting. Subsequent attempts, on processing of these alloys, demonstrated the effectiveness of rheocasting (Ichikawa and Ishizuka 1987; Pathak and Tiwari 1993), compocasting (Pathak and Tiwari 1991), stir casting (Mohan et al 1989) and impeller mixing and chill casting (Pathak et al 1995) methods to achieve uniform dispersion of $\mathrm{Pb}$-particles in $\mathrm{Al}$-matrix. In different variants of these techniques, the melt is vigorously stirred prior to chill casting. Nevertheless, the degree of melt stirring, pouring temperature and thermal conductivities of the mould materials considerably influence the nature of dispersion of the second phase particles in these processes. In a recent investigation, Ojha et al (1994) employed the spray casting process to synthesize liquid immiscible alloys with ultrafine dispersion of second phase particles. In this technique, the melt was gas atomized from the 
temperature above the liquid immiscible regime of the alloy and deposited over a substrate into high-density preform. Rapid solidification of atomized droplets vis-a-vis that of the deposit due to high heat exchange rate at the droplet-gas interface and also on the deposition surface resulted in effective control of the size of second phase particles in the matrix phase.

The present investigation is aimed at evaluating the effect of two potentially different processing methodologies on the microstructure, mechanical property and wear characteristics under dry sliding of an $\mathrm{Al}-4 \cdot 5 \mathrm{Cu}-10 \mathrm{~Pb}$ alloy. The techniques employed in the present work to synthesize the alloy consisted of spray casting and impeller mixing followed by chill casting.

\section{Experimental}

\subsection{Material preparation}

An $\mathrm{Al}-4 \cdot 5 \mathrm{Cu}-10 \mathrm{~Pb}$ alloy was prepared from commercial purity metals. The melting was carried out in a graphite crucible using a resistance heating furnace. A continuous supply of argon gas was maintained in the crucible to protect the melt from oxidation. The details of the spray casting process employed to produce the preform has been described elsewhere (Ojha et al 1992). In brief, the process consisted of atomization of the melt by high-energy $\mathrm{N}_{2}$ gas jets at 1.2 MPa pressure followed by deposition of the spray of droplets on a copper substrate. The melt temperature of $1373 \mathrm{~K}$ was used to ensure complete miscibility of the liquid phase prior to atomization of the melt. The nozzle to substrate distance of $0.3 \mathrm{~m}$ was consistently maintained to produce a preform with a diameter of $10 \mathrm{~cm}$ and $25 \mathrm{~cm}$ thickness.

In another experiment an impeller mixing and chill casting process was employed to synthesize the alloy in the form of an ingot. The salient features of the technique have been described by Pathak et al (1993). The melt in this process was vigorously stirred using a high speed stirring device in a crucible and bottom poured into a cast iron mould from a melt temperature of $973 \mathrm{~K}$. Cylindrical specimens of $8 \mathrm{~mm}$ dia $\times 50 \mathrm{~mm}$ length were machined from both the spray deposit and cast ingot for wear testing.

\subsection{Mechanical testing}

Mechanical properties of the spray formed and impeller mixed chill cast alloys were evaluated at room temperature using instron testing machine. Tensile and compressive strengths were measured at a cross head speed of $2 \mathrm{~mm} \mathrm{~min}^{-1}$. Specimens with $16 \mathrm{~mm}$ length and $4.5 \mathrm{~mm}$ gauge diameter were used for the tensile test whereas compressive tests were carried out on cylindrical samples with $10 \mathrm{~mm}$ length and $8 \mathrm{~mm}$ diameter. The hardness measurements were carried out using a Brinell hardness tester under an applied load of $50 \mathrm{~kg}$ for a duration of $30 \mathrm{sec}$.

\subsection{Wear test procedure}

The wear test was carried out on an indigenously developed pin-on-disc machine. The details of the set-up are described elsewhere by Pathak et al (1993). Primarily the set-up 
consisted of a hardened steel disc of $120 \mathrm{~mm}$ diameter connected to a variable speed d.c. motor through a shaft driven by pulley and belt system. The wear test specimen was mounted in a specimen holder attached to the bottom of load pan facing towards the steel disc. The traversing of the specimen holder on the disc facilitated the selection of wear track diameter in this process. The flat surfaces of both the test pin and steel disc were polished to a surface roughness of about $0.5 \mu \mathrm{m}$, thoroughly degreased and dried before the test. The diameter of the wear track was varied from 20 to $100 \mathrm{~mm}$ by controlled movement of the specimen holder. The sliding velocity of the test pin from 0.2 to $1.6 \mathrm{~ms}^{-1}$ was regulated through the speed of the motor and diameter of the wear

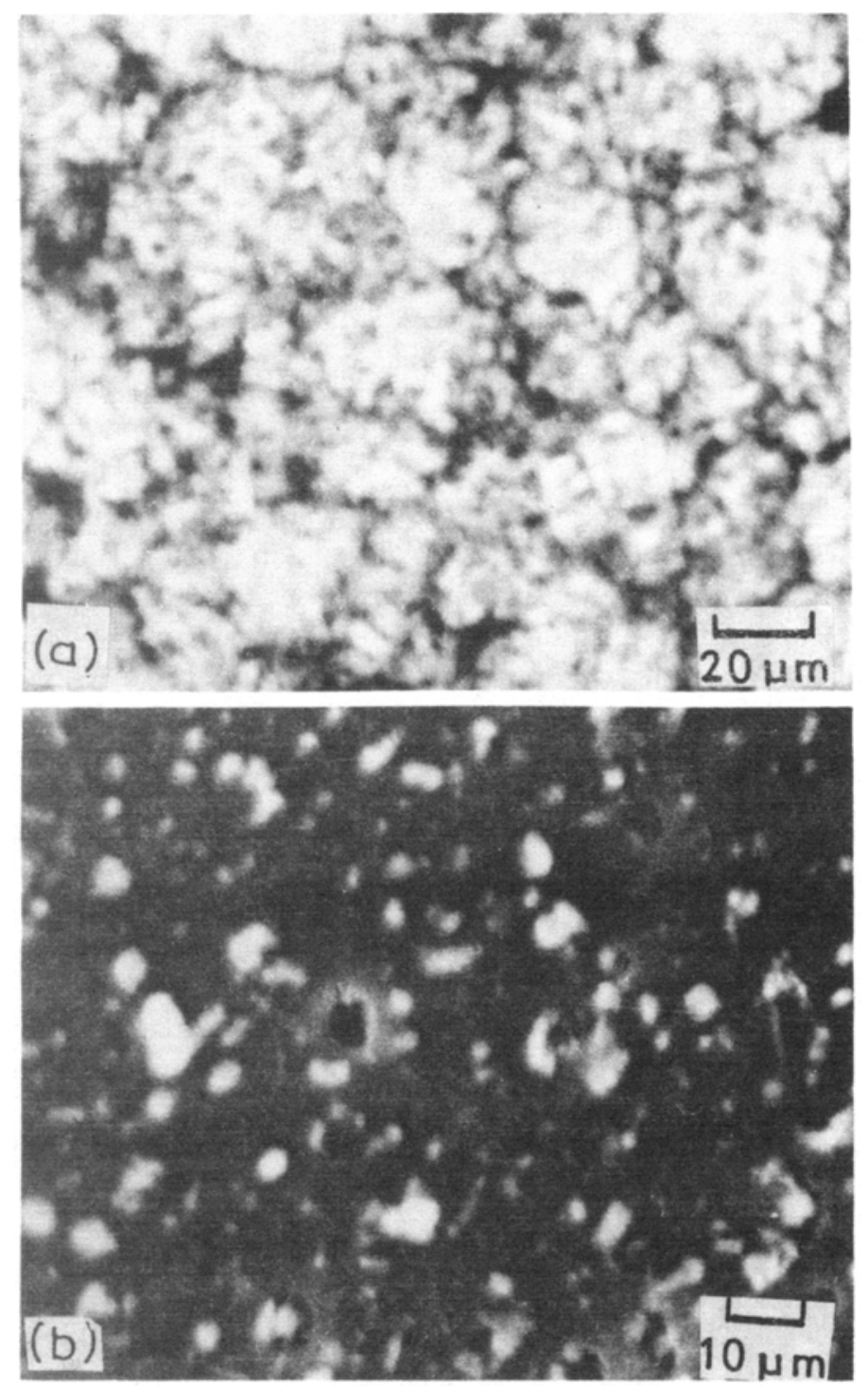

Figure 1. Microstructure of the spray formed $\mathrm{Al} \cdot 4 \cdot 5 \mathrm{Cu}-10 \mathrm{~Pb}$ alloy showing (a) equiaxed grain morphology and (b) dispersion of $\mathrm{Pb}$-particles in the matrix. 
track. In this experiment the applied load of $15 \mathrm{~N}$ was consistently maintained. Subsequently the applied load was varied from 5 to $35 \mathrm{~N}$ at a constant sliding velocity of $0.5 \mathrm{~ms}^{-1}$. The difference in weight of the test specimen before and after the test provided the weight loss due to wear and this was monitored at regular intervals. The measurement in weight by an electrical balance was ensured within an accuracy of $\pm 10^{-8} \mathrm{~kg}$. The wear volume was determined from the data on weight loss measurements. In the present experiment all the tests were carried out in dry sliding conditions and data recorded at room temperature.

\subsection{Microscopy}

The specimens $\left(10 \times 10 \times 5 \mathrm{~mm}^{3}\right)$ from the spray deposit and cast ingot were prepared for the microstructural investigation using standard metallographic procedures of grinding and polishing. These were etched with a $5 \%$ nital and examined in a Leitz optical metallograph. A Jeol 840-A CX scanning electron microscope operating at $15 \mathrm{kV}$ was used to study the surface topography of the worn out test pieces and debris particles.

\section{Results and discussion}

\subsection{Microstructural characteristics}

The microstructure of the spray cast alloy invariably showed an equiaxed grain morphology of the primary phase with a fine dispersion of Pb-particles in Al-matrix (figures $1 \mathrm{a}$ and $\mathrm{b}$ ). The grain size varied from 10 to $25 \mu \mathrm{m}$ in the deposit near the contact surface with the deposition substrate. This section of the deposit also revealed a large number of finite size porosity varying from 5 to $25 \mu \mathrm{m}$ size. However, the amount of porosity considerably decreased in the deposit away from the contact surface. An increase in grain size was observed in the centre and top section of the deposit. Still this area of the deposit exhibited an average grain size of $25 \mu \mathrm{m}$. Scanning electron microscopy indicated that the porosities were mostly isolated and formed along the grain boundaries of the matrix phase (figure $2 \mathrm{a}$ ). The $\mathrm{Pb}$-particles on the other hand, were observed to be uniformly distributed within the equiaxed grains of the primary phase with some notable exceptions of $\mathrm{Pb}$-rich phase formed in the intergranular region (figure $2 b$ ).

The microstructural examination of the alloy, produced by the impeller mixing and chill casting process, unequivocally exhibited cellular-dendritic morphology of the primary phase (figures $3 a$ and $b$ ). The cellular region was observed to decrease from chill surface to the centre of the ingot. The $\mathrm{Pb}$-rich phase was often observed to be in the intercellular and interdendritic regions of the primary phase (figures $4 a$ and b).

The above microstructural variation in $\mathrm{Al}-4 \cdot 5 \mathrm{Cu}-10 \mathrm{~Pb}$ alloy primarily arises due to different solidification conditions prevailing during the spray casting as well as in the impeller mixing and chill casting process. In the former, a wide size range of droplets impinge on the deposition surface with their different thermal state and velocities. An analysis of droplet dynamics and heat transfer from atomized droplets by Singh et al (1992) illustrated that in a typical spray forming condition small size droplets less than $25 \mu \mathrm{m}$ fully solidify whereas large size droplets greater than $150 \mu \mathrm{m}$ remain fully liquid 

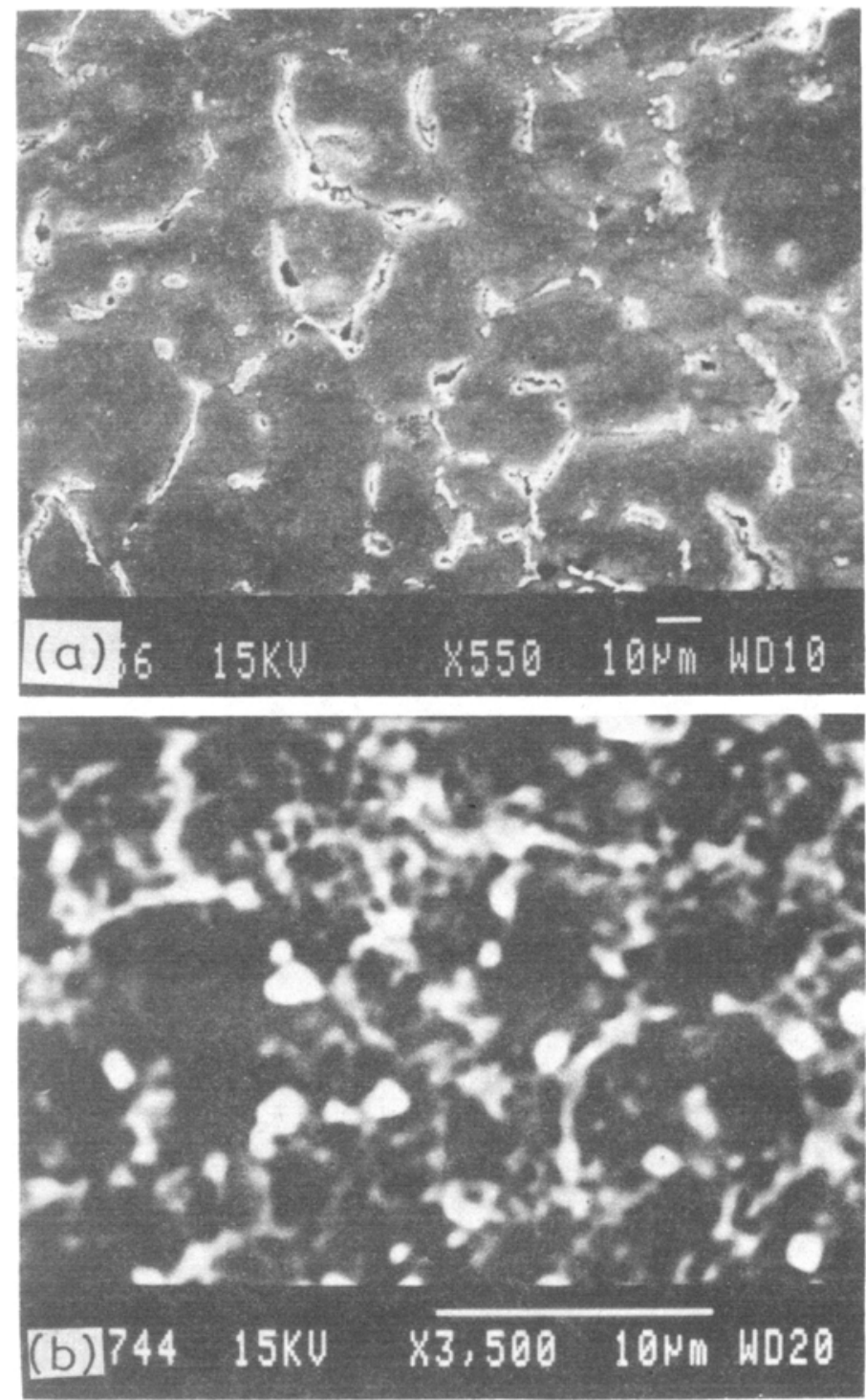

Figure 2. Scanning electron micrograph showing (a) formation of porosity along the grain boundaries and (b) ultrafine Pb-particles.

and several intermediate size droplets are in semi-solid state during deposition on the substrate. Coalescence of droplets with different thermal states then occurs on the deposition surface due to high temperature. It was shown that high-velocity droplets transfer considerable mechanical momentum in the liquid phase on deposition surface. This effect induces turbulent fluid flow condition and a shearing action of the semi-solid mass resulting in fragmentation of dendrites and large size droplets of $\mathrm{Pb}$-rich liquid on the deposition surface (Ojha et al 1993). The homogenization of temperature and composition of the liquid due to turbulent fluid flow provides a condition for non-dendritic growth of the primary phase (Flemings 1974). Furthermore, large 

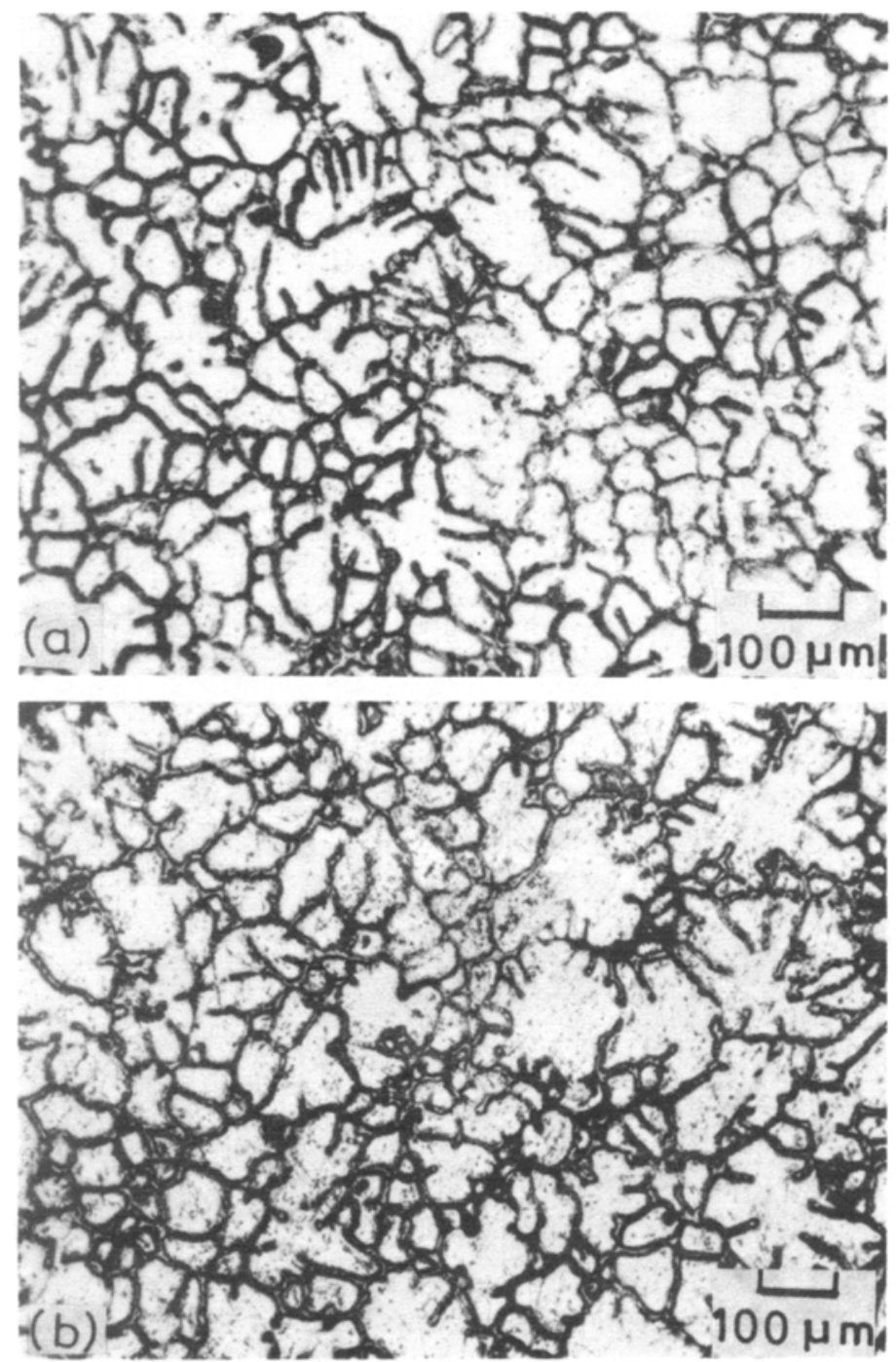

Figure 3. a and b. Microstructure of impeller mix and chill cast alloy showing co-existing cellular-dendritic morphology.

amount of debris generated due to the fragmentation of dendrites enhances the nucleation rate of crystals during subsequent stages of solidification of the melt (Lavernia 1989). The crystals growing from different sites meet on common boundaries to generate equiaxed grain morphology of the primary phase. The small size droplets of $\mathrm{Pb}$-rich liquid are entrained by the multi-interfaces during growth of the equiaxed crystals. This effect provides uniform dispersion of $\mathrm{Pb}$-particles in the matrix phase.

On the other hand, in impeller mixing and chill casting process although homogenization of the melt is achieved during stirring stage but its subsequent solidification in the mould further causes segregation of Pb-rich liquid (Pathak et al 1995). However, high heat exchange rate at the mould-liquid interface generates cellular solidification structure in the ingot near the mould wall. As the solid-liquid interface advances away 
from the mould wall, the cooling rate of the casting slows down. The interface instability arising during this stage gives rise to formation of dendritic structure in this area of the ingot. During further solidification of the melt, the $\mathrm{Pb}$-rich phase is confined mostly in the intercellular or interdendritic regions.

\subsection{Mechanical property}

Table 1 shows the mechanical properties of the alloys under investigation. The data on mechanical properties of an $\mathrm{Al}-4 \cdot 5 \mathrm{Cu}$ alloy is also included for comparison. The result
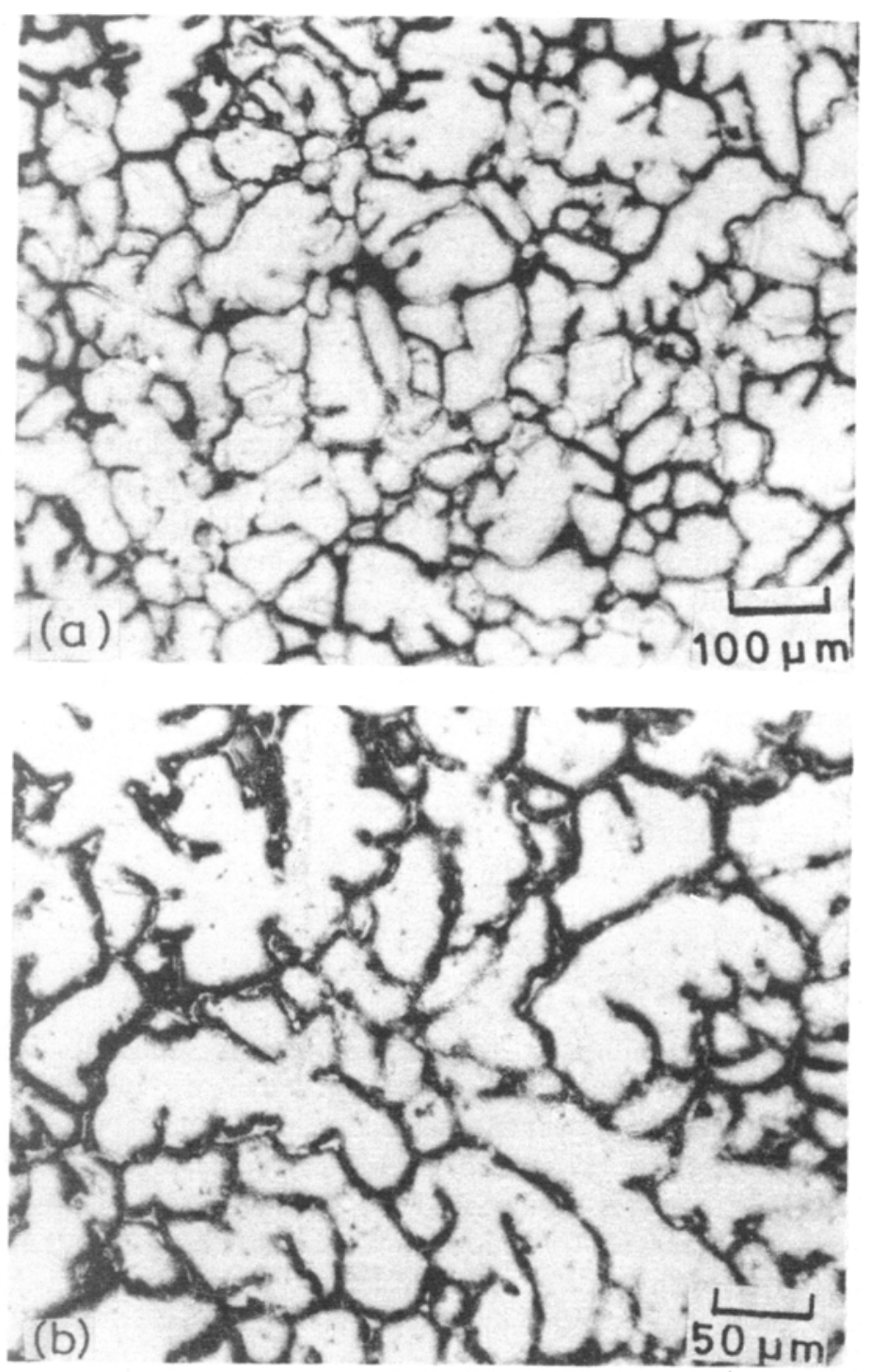

Figure 4. a and $\mathrm{b}$. Microstructure of $\mathrm{Al}-4 \mathrm{Cu}-10 \mathrm{~Pb}$ alloy showing $\mathrm{Pb}$-phase in the intercellular or interdendritic region. 
Table 1. Mechanical properties of $\mathrm{Al}-4 \cdot 5 \mathrm{Cu} \cdot 10 \mathrm{~Pb}$ alloy

\begin{tabular}{|c|c|c|c|c|c|c|}
\hline $\begin{array}{l}\text { Alloy } \\
\text { composition } \\
(w t \%)\end{array}$ & $\begin{array}{l}\text { Processing } \\
\text { method }\end{array}$ & $\begin{array}{c}\text { UTS } \\
\left(\mathrm{MN} \mathrm{m}^{-2}\right)\end{array}$ & $\begin{array}{c}0.2 \% \\
\text { tensile } \\
\text { proof } \\
\text { stress } \\
\left(\mathrm{MN} \mathrm{m}^{-2}\right)\end{array}$ & $\begin{array}{c}0.2 \% \text { com- } \\
\text { pressive } \\
\text { proof } \\
\text { stress } \\
\left(\mathrm{MN} \mathrm{m}^{-2}\right)\end{array}$ & $\begin{array}{c}\text { Hardness } \\
\text { (BHN) }\end{array}$ & $\begin{array}{c}\text { Elongation } \\
(\%)\end{array}$ \\
\hline $\mathrm{Al}-4 \cdot 5 \mathrm{Cu}$ & $\begin{array}{l}\text { Impeller } \\
\text { mix chill cast }\end{array}$ & 196.8 & $141 \cdot 2$ & $174 \cdot 3$ & $57 \cdot 0$ & $10 \cdot 8$ \\
\hline $\begin{array}{l}\mathrm{Al}-4 \cdot 5 \mathrm{Cu}- \\
10 \mathrm{~Pb}\end{array}$ & $\begin{array}{l}\text { Impeller } \\
\text { mix chill cast }\end{array}$ & $152 \cdot 6$ & $96 \cdot 1$ & $141 \cdot 2$ & $48 \cdot 1$ & $12 \cdot 1$ \\
\hline $\begin{array}{l}\mathrm{Al}-4 \cdot 5 \mathrm{Cu}- \\
10 \mathrm{~Pb}\end{array}$ & $\begin{array}{l}\text { Spray } \\
\text { formed }\end{array}$ & $160 \cdot 0$ & 117.2 & $151 \cdot 6$ & $54: 2$ & $11 \cdot 7$ \\
\hline
\end{tabular}

indicates that the hardness and tensile strength of spray cast alloy is more than that of the alloy produced by the impeller mixing and chill casting process. Furthermore, the addition of $\mathrm{Pb}$ to the $\mathrm{Al}-4 \cdot 5 \mathrm{Cu}$ alloy gives rise to a decrease in its mechanical properties. This effect is consistent with the earlier work of Pathak et al (1995). Lead is a soft constituent which lowers the tensile strength of $\mathrm{Al}-4 \cdot 5 \mathrm{Cu}$ alloy but at the same time the percentage elongation is increased due to its presence in the matrix phase. Lead is present in the interdendritic regions of aluminium-copper alloy. As a result, this phase lowers the bonding strength of the grain boundary regions. Lead is a highly soft material and it deforms extensively as compared to the less plastic Al--4.5Cu matrix alloy. Further, in the process of straining lead does not work harden as it recrystallizes below room temperature. These characteristics of lead may account for a decrease in tensile properties and increase in ductility of $\mathrm{Al}-4 \cdot 5 \mathrm{Cu}$ matrix alloy. It is also marked that spray cast alloys show a higher hardness and tensile as well as compressive strengths compared to impeller mixed chill-cast alloys. This may be due to the different morphology of lead particles and their size and size distribution in the matrix phase. Lead phase is more continuous in the interdendritic regions of impeller mixed, chill-cast alloys in contrast to isolated particles of lead in the spray formed alloy. The result of the present work is consistent with that of earlier work of Pathak et al (1986), wherein considerable effect of lead on the mechanical properties of alloy was reported.

\subsection{Wear characteristics}

Variation in wear rate of the alloy measured as a function of applied load is shown in figure 5. The result of the present work indicates that there are two distinct regions of wear. The first regime of mild wear is observed under the applied load condition of 5 to $15 \mathrm{~N}$. The second regime pertains to severe wear under high load (20 to $30 \mathrm{~N})$ condition. Mild wear increases rapidly after the load of $15 \mathrm{~N}$ and becomes severe beyond $20 \mathrm{~N}$ load. Thus there is a transition range of loads of $15 \mathrm{~N}$ to $20 \mathrm{~N}$ under which wear rate is not linear with load though mild and severe types of wear have linear relation with load which reflects the laws of adhesive and abrasive wear of metallic materials (Sarkar 1976).

Figure 6 shows a relation between the wear rate and the sliding velocity. It is seen that in the beginning the wear rate decreases with sliding velocity, attains a minimum 


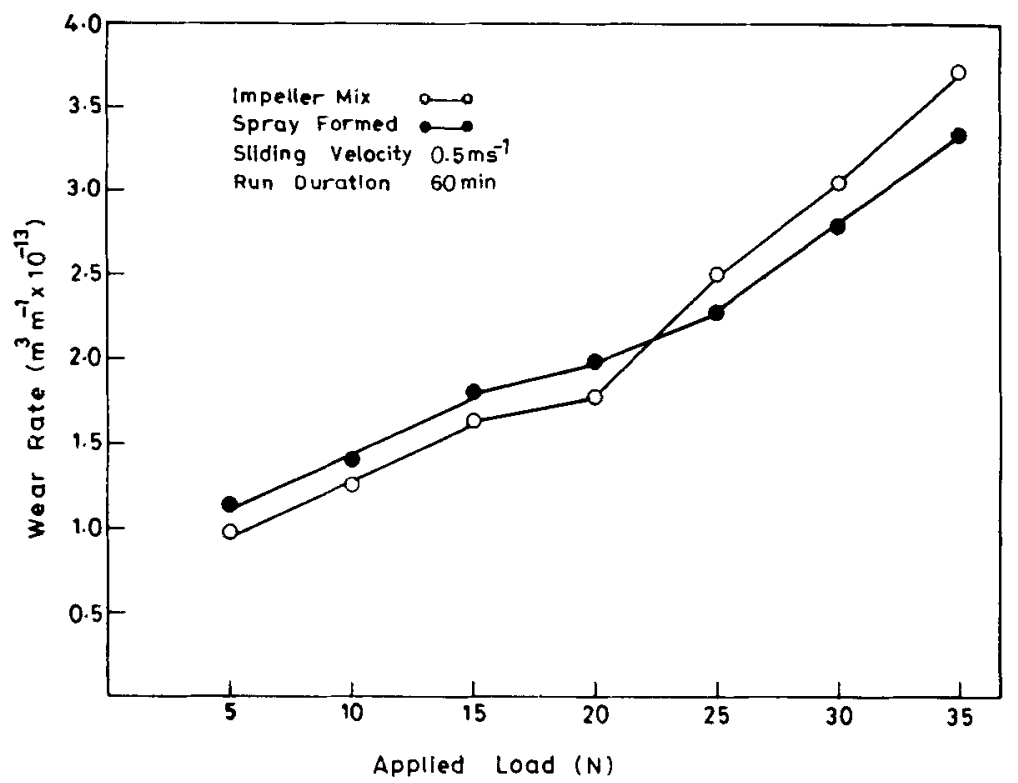

Figure 5. Variation in wear rate of $\mathrm{Al}-4 \cdot 5 \mathrm{Cu} 10 \mathrm{~Pb}$ alloy with applied load.

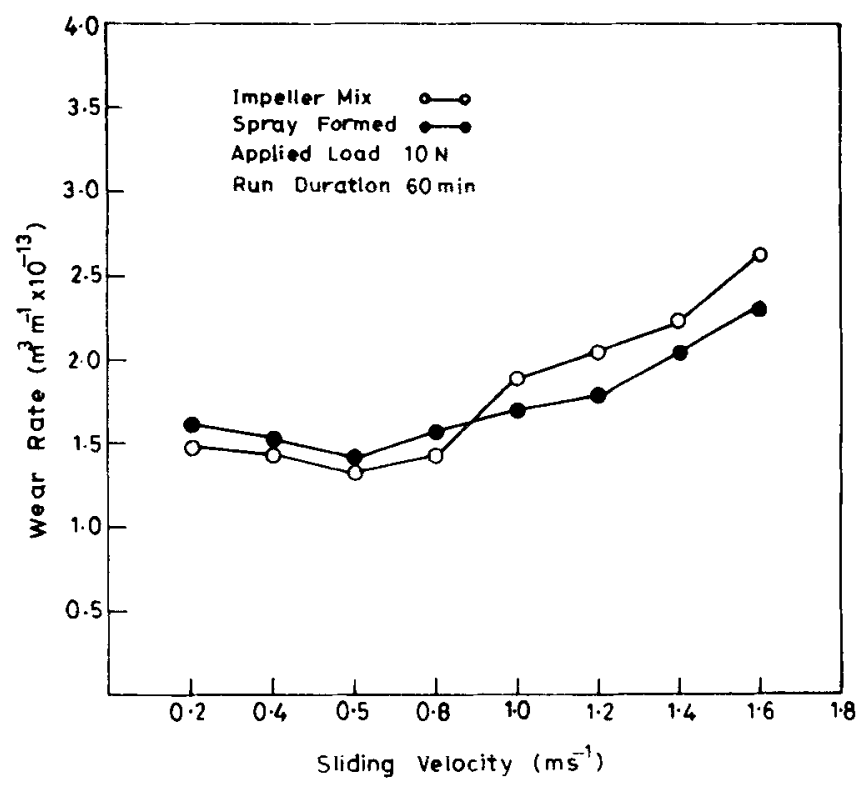

Figure 6. Effect of sliding velocity on wear rate of $\mathrm{Al} 4 \cdot 5 \mathrm{Cu}-10 \mathrm{Ph}$ alloy.

value and then further increases with increase in sliding velocity. Earlier workers have also reported a similar trend after studying the effect of sliding velocity on the wear rate of metals and alloys (Pathak et al 1986; Mohan ef al 1989). It has been explained that lead acts as a solid lubricant between the mating surfaces by smearing over the substract and forming a lead film (Lun 1957). In the present case also the hard and 
strong matrix of $\mathrm{Al}-4 \cdot 5 \mathrm{Cu}$ alloy, is forced deeper by the asperities present on the surfaces which causes extrusion and smearing of lead over the test pin surface as shown in figures 7 and 8 . On further sliding of the pin, lead is built up over the pin surface and a film is formed between the mating surfaces which works as solid lubricant and reduces the wear of the matrix phase. It is also seen from figure 5 that impeller mix alloy shows a low wear rate in the mild wear regime compared to that of spray formed alloy, whereas in severe wear regime the spray formed alloy exhibits a relatively low wear rate compared to alloy produced by impeller mixing method. This may be attributed to the morphology of lead particles present in the respective alloys. The nature of the
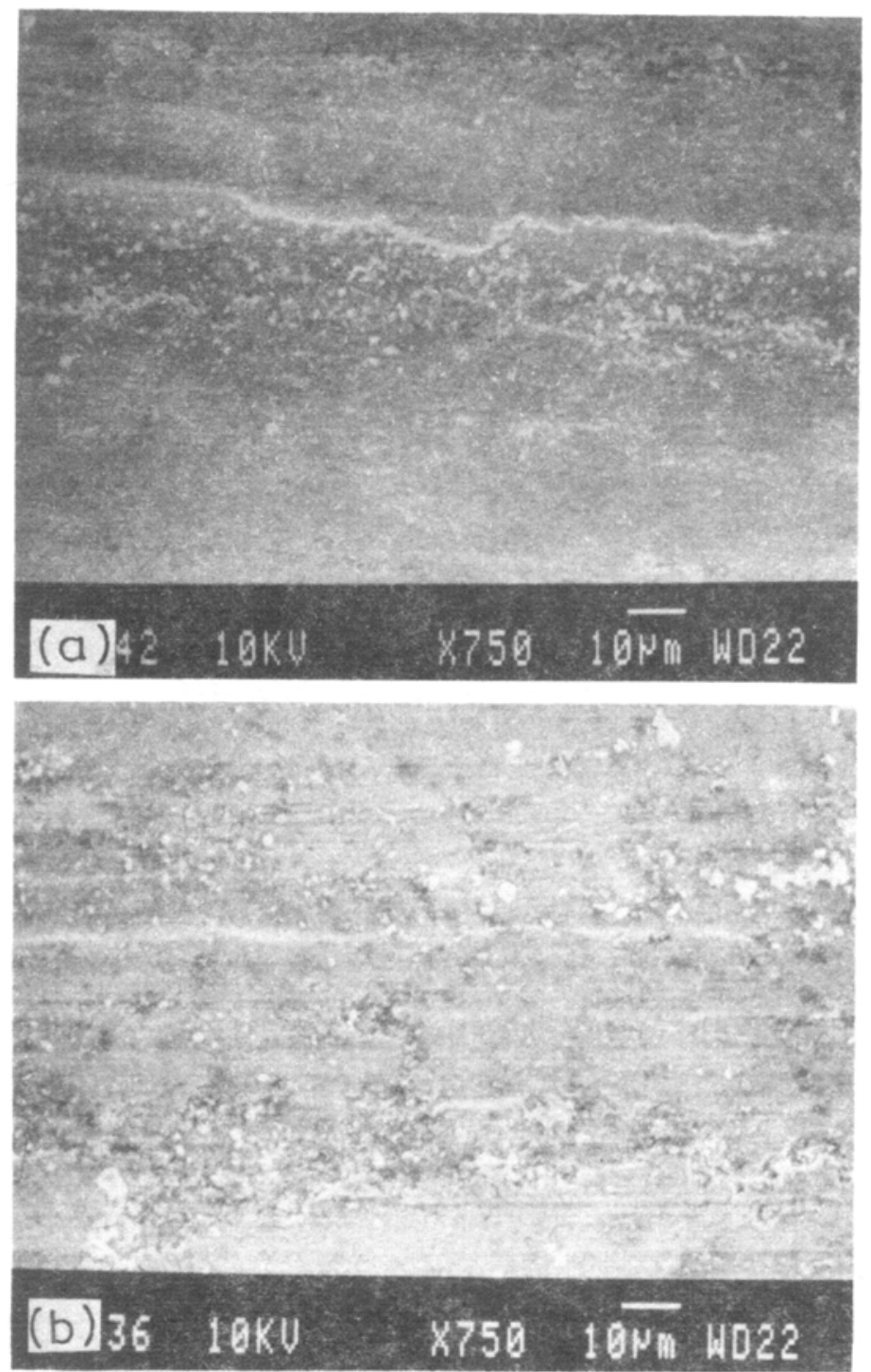

Figure 7. Scanning electron micrograph of worn out surface of specimen prepared from impeller mixed alloy at applied load of (a) $10 \mathrm{~N}$ and (b) $30 \mathrm{~N}$. 

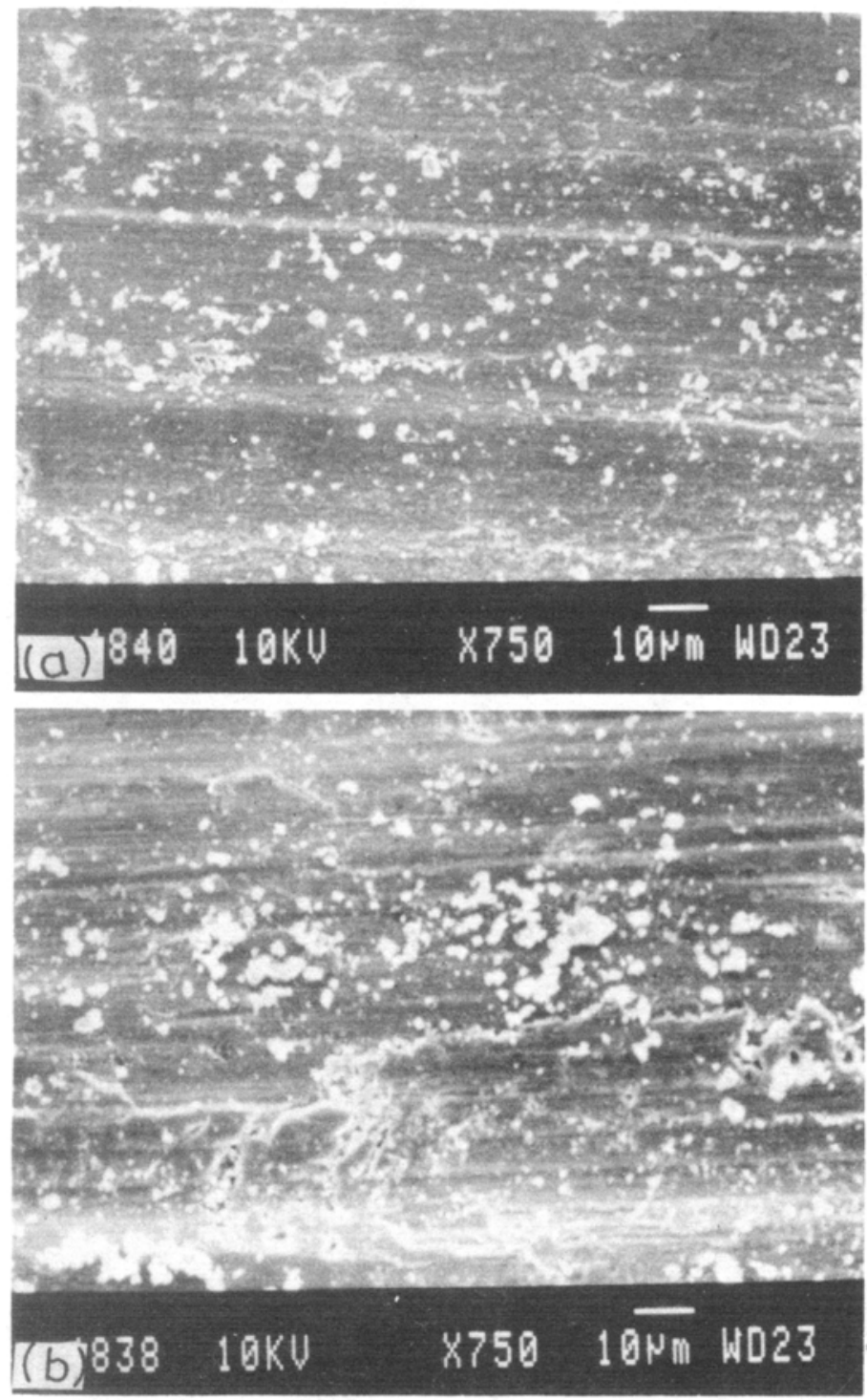

Figure 8. Scanning electron micrograph of worn out surface of specimen from spray formed alloy at applied load of (a) $10 \mathrm{~N}$ and (b) $30 \mathrm{~N}$.

distribution of lead not only affects the wear rate but also influences the mechanical properties of the alloy.

Lead phase in impeller mix alloy forms a continuous network in the interdendritic regions as shown in figure 4 . In contrast, the lead particles are discontinuous in spray formed alloy. This typical morphology of lead dispersion in impeller mix alloy causes lower strength and hardness properties than the spray formed alloy. However extrusion and smearing of lead on the substract is more easily generated in case of impeller mixed alloy (figure 7a) compared to that in the spray formed alloy (figure 8a). Consequently wear rate of the former is lower than the later at low load condition. Under high 

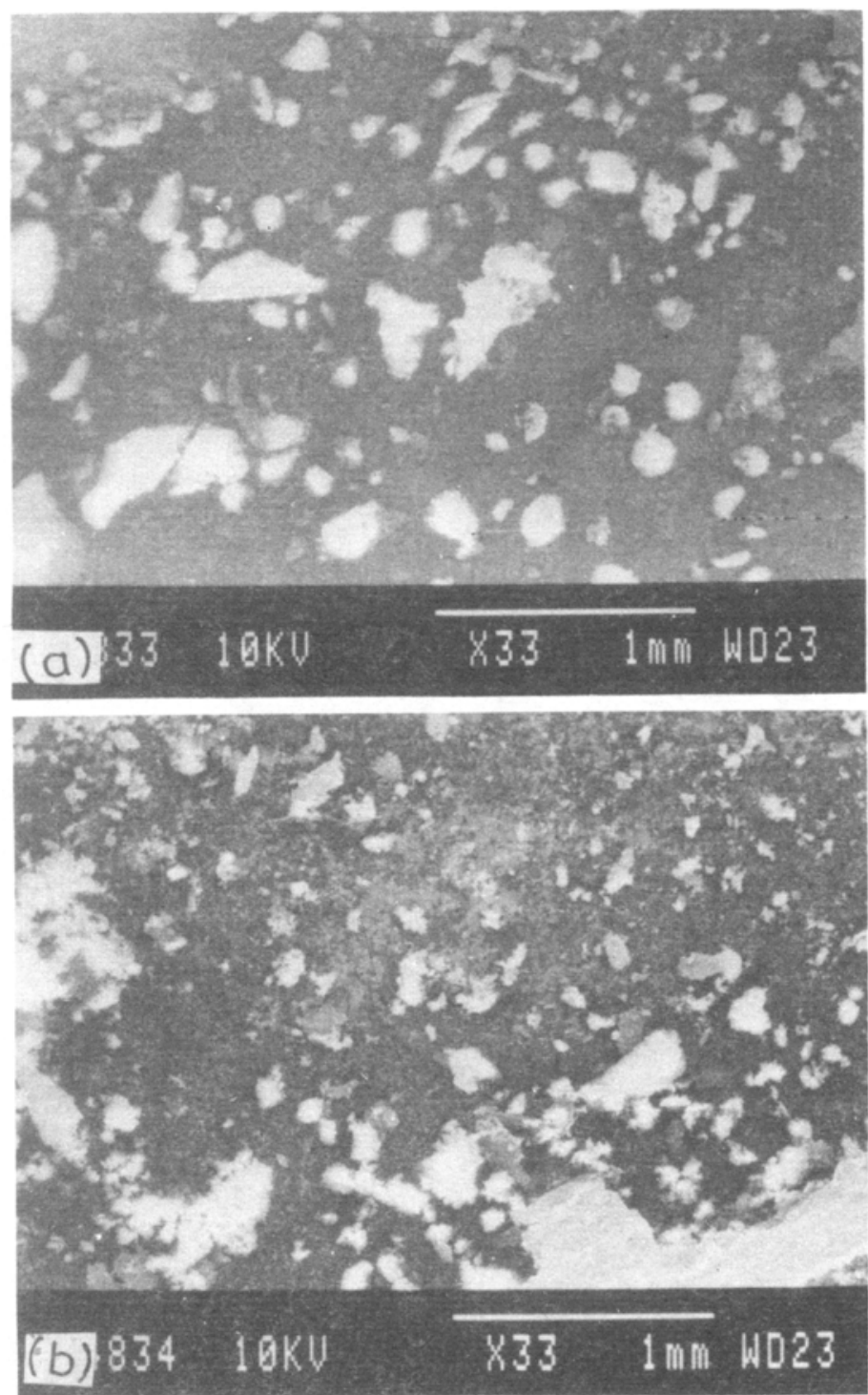

Figure 9. Scanning electron micrograph of debris particles of specimen from (a) impeller mixed and (b) spray formed alloys.

load condition the trend is reversed because the mechanical properties of the alloy starts dominating under this condition. It can be inferred that under severe test condition the low strength impeller mix alloy plastically flows at an early stage compared to high strength spray formed alloy. As a result, this phenomenon causes more distortion and wear of the pin on the mating surface of the impeller mix alloy in comparison to the spray formed alloy. The nature of the worn out surfaces and also the size of debris particles justify this explanation (figures $7 \mathrm{~b}$ and $8 \mathrm{~b}$ ).

The initial decrease of wear rate under low sliding velocity may be visualized due to a rise in the temperature of the mating surfaces which promotes formation of protective 
films of lead thereby lowering the wear rate. However, when the sliding velocity exceeds a critical value the $\mathrm{Pb}$-film in the alloy becomes discontinuous and consequent increase in the wear rate takes place. The impeller mix alloy has low hardness and strength compared to spray formed alloy (table 1). Consequently the effect of higher sliding velocity is more pronounced which results in higher wear rate. In the beginning impeller mix alloy shows lower wear rate than the spray formed alloy due to formation of protective films at an early stage and facilitates lead extrusion and smearing on the substrate surface. Scanning electron micrographs as shown in figures $9 a$ and $b$ of the debris show co-existing fine and coarse mixture of lead and oxide particles which are produced due to the transfer of lead from the test pin caused by adhesion and shearing of the junctions between the mating surfaces. Thus the results of the present investigation indicate that an effective control of the processing condition leads to an improvement in wear characteristics of $\mathrm{Al}-4 \cdot 5 \mathrm{Cu}-10 \mathrm{~Pb}$ alloy.

\section{Conclusions}

The microstructure of $\mathrm{Al}-4 \cdot 5 \mathrm{Cu}-10 \mathrm{~Pb}$ alloy produced by spray forming process showed an equiaxed grain morphology with uniform dispersion of lead particles in the matrix. In contrast, the solidification structure of the alloy produced by impeller mixing followed by chill casting process indicated co-existing cellular-dendritic morphology of the primary phase with lead in the interdendritic or intercellular region.

The hardness and tensile strength of the spray formed alloy were more than that of the alloy produced by impeller mixed chill casting method. The wear rate of the spray formed alloy under an applied load of 25 to $35 \mathrm{~N}$ and sliding velocity of 1.0 to $1.6 \mathrm{~ms}^{-1}$ was lower than that of the chill-cast alloy. A reverse trend in the wear rate of the alloy was the characteristic feature at low load and sliding velocity. An analysis of the worn out surfaces of the test pin and wear debris particles provided the explanation for this behaviour.

\section{Acknowledgements}

The authors thank the Head, Department of Metallurgical Engineering, Banaras Hindu University, Varanasi, for providing the necessary facilities to carry out the present work.

\section{References}

Burbunov V G. Parshin V D and Panin V V 1973 Russian Cast. Prod. 9353

Eppich R E, Mebbers F J and Dawson R N 1971 Met. Engy. Quart. 1133

Flemings M C 1974 Solidification processing (New York: McGraw-Hill) p. 266

Forrester P G 1960 Metall. Rev. 507

Ichikawa K and Ishizuka S 1987 Trans. Jap. Inst. Metals 28145

Lavenia E J 1989 Int. J. Rapid Solidification 547

Lun B 1957 Wear 125

Mohan S, Agarwala V and Ray S 1989 Z. Metallkunde 80556

Mondolfo L F 1976 Aluminium alloys: Structure and properties (London: Butterworth) p. 352

Ojha S N, Mandal R K and Gauthama 1994 in Noct techniques in synthesis and processing of advanced materials (eds) J Singh and S M Copley (Warrendale, Pennsylvania: TMS) p. 375 
Ojha S N, Pandey O P, Tripathi B, Kumar M and Ramachandra C 199233519

Ojha S N, Tripathi A K and Singh S N 1993 Powder Met. Int. 265

Pathak J P, Karimi D and Tiwari S N 1993 Wear 107109

Pathak J P, Tiwari S N and Malhotra S L 1986 Wear 112341

Pathak J P and Tiwari S N 1991 Trans. Indian Inst. Metals 144341

Pathak J P and Tiwari S N 1992 Wear 15537

Pathak J P and Tiwari S N 1993 India Foundry J. 143

Pathak J P, Torbian H and Tiwari S N 1995 Cast Metals 7201

Pratt G C 1973 Inter. Metall. Rev. 1862

Sarkar A D 1976 Wear of metals (Oxford: Pergamon) p. 49

Singh S N, Mishra N S and Ojha S N 1992 Steel Res. 6312 